International Journal of English Literature and Social Sciences
Vol-6, Issue-3; May-Jun, 2021
Journal Home Page Available: https://ijels.com/
Journal DOI: $10.22161 /$ ijels

Peer-Reviewed Journal

\title{
Implementation of RA 10586 (Anti-drunk and Drugged Driving Act of 2013)
}

\author{
Jonah B. Badua
}

College of Criminal Justice Education, Northwestern University, Laoag City Philippines

Received: 01 Mar 2021; Received in revised form: 04 Apr 2021; Accepted: 25 Apr 2021; Available online: 17 May 2021

(C)2021 The Author(s). Published by Infogain Publication. This is an open access article under the CC BY license

(https://creativecommons.org/licenses/by/4.0/).

\begin{abstract}
The prevalence of drunk driving incidences is alarming which significantly contributes on the causes of death and physical impairment. The anti-drunk driving law was established and being implemented, however drunk driving prevails. Few apprehensions are just recorded. It assessed the implementation of RA 10586 (Anti-Drunk and Drugged Driving Act of 2013). It involved 114 motorist and 71 law enforcement officers from Laoag and Batac City and municipality of San Nicolas. This study used descriptive research design through a questionnaire, and unstructured interview. Random sampling was used for motorist and total enumeration for law enforcement officers. All the motorist are males, single, young-adult, college level, employed, have a drivers license with sufficient experienced however they lack seminar on RA 10586. The law enforcement officers are male dominated, married, young-adult, and attained college level. Majority are traffic enforcers and stayed long in the service and have some seminars and trainings related to $R A 10586$ and the traffic rules and regulations. The implementation of RA 10586 is often implemented, but there are also specific provisions of which they perceived differently, like in apprehension (motorists =often; LEO = always) and information, education, and communication campaign (motorist =often; $L E O=$ sometimes). Law enforcers have very minimal involvement in IEC. Motorists claimed that the law enforcers are lax, discourteous and show misconduct. Corruption is not a problem. Law enforcers disclosed that motorists display disrespect, offer a bribe as an option for non-issuance of ticket, and escape penalties and dishonesty.
\end{abstract}

Keywords—driving, drunk, implementation, motorist, enforcement.

\section{INTRODUCTION}

"Do not Drink and Drive", this is a saying which is common to all and usually within the tip of the tongue of all motorists. This statement serves as a reminder for every motorists not to drive vehicle under the influence of liquor to ensure road safety. However, despite of knowing this in mind the motorists failed to observe as a result, drunkdriving violation is committed.

Road-traffic collisions are responsible for 1.2 million deaths and as many as 50 million injuries annually according to estimates by the World Health Organization. Although death and injury due to road-traffic collisions have decreased in recent years in many high-income countries, their burden remains a large contributor to overall mortality and morbidity (Cinnamon et al., 2011). More than $90 \%$ of drivers engaged in some form of risky driving behavior (Fergusson et al., 2008) which is mostly attributed to alcohol drinking.

Brady and Li (2012) examined the prevalence of alcohol and other drugs (AOD) in a large sample of fatally injured drivers using data from the Fatality Analysis Reporting System for 2005-09, the United States. Findings showed that drivers who died within 1 hour of the crash underwent toxicological testing on more than $80 \%$ of these drivers. Of the 20150 fatally injured drivers studied, $57.3 \%$ tested positive for AOD, including $19.9 \%$ being positive for two or more substances. Alcohol was the most commonly detected substance, present in $40.2 \%$ of the 
fatally injured drivers, followed by cannabinols (10.5\%), stimulants $(9.0 \%)$, narcotics $(5.7 \%)$ and depressants $(4.0 \%)$.

Reynaud, M. et al. (2002) also studied alcohol related accidents wherein a positive results of the alcohol tests were known in $78.7 \%$ of the drivers. Their blood alcohol concentration exceeded the limit $(0.50 \mathrm{~g} / \mathrm{L}$ in France) which causes casualties and fatal wounds.

O'Connor and Ruiz (2014), on road traffic injuries in the Philippines, it highlights that there are 1.24 million deaths due to road traffic injuries and majority occur in low- and middle-income countries. With this alarming situation, 35 countries passed legislation to implement road safety strategies however many countries have yet to pass comprehensive legislation while others lack adequate enforcement of current policies. A drunk driver has a higher risk of being killed in a vehicular accident than those who do not drunk drive. The number of vehicular accidents associated with drunk driving is increasing (Felipe, 2016).

In Tan (2018), the Land Transportation Office (LTO) reported that few violators were caught for RA 10586, which is only 101 motorists for six months in the country and are first-time offenders. In 2015, the agency had provided a total of 756 breath analyzers to the Philippine National Police (PNP) and its offices in different regions and deputized 818 personnel coming from various government agencies including the LTO, PNP, and Metropolitan Manila Development Authority (MMDA) to arrest violators. In Region 1, the Land Transportation Office conducted a three-day Deputization and Traffic Law Enforcement seminar for 116 police officers for deployment in the highways as LTO Deputized Enforcers. The policemen are deputized to help reduce the incidence of traffic accidents by irresponsible and reckless drivers through strict enforcement of traffic rules and to discipline drivers. The deputized 116 policemen will complement the LTO enforcers in the region in enforcing traffic rules and regulations. They also help educate motorists and impose discipline on the highways. Most of the road accidents is attributed to abusive drivers and motorists who do not know the meaning of traffic signs and warnings.

Dacalanio (2017) disclosed that the traffic enforcers attained college level or college graduates and rendered service for ten years and are young. Traffic enforcers revealed that they are moderately competent in terms of traffic laws and orders, displaying traffic officer personality, keeping records of all violations, traffic procedures, and educating people on traffic safety.
Bornewasser, M. and Glitsch, E. (2000) determined the decision making of drivers cognitions and motives underlying decision making in drunk driving. It involved 185 drivers who are officially registered and not detected for drunk driving. Findings revealed that there is a lack of inhibiting feelings in the group of detected drivers and have a greater tendency to neglect social norms and lower possible risks of detection and accident. There is a high prevalence of alcohol abuse, and a lot of drunk driving and, round about $10 \%$ of all incidents are alcoholrelated.

Miguel et al., (2014) studied traffic rules and regulations of motorists in San Nicolas and found out that most of the traffic violators are male and young. Driving without a license or expired license is mostly violated, followed by no entry, disregarding traffic signs, driving for hire on sleepers or short pants, and no OR or CR. The National Law on the use of a helmet lacks full implementation. Traffic violations have a significant increase every year.

Ying et al., (2013) determined the impact of drinking and driving laws on drinking and driving fatality rates. It explored the different effects these laws have on areas with varying severity rates for drinking and driving. Policies must be in place to effectively reduce drunk driving fatality rates considering specific conditions in various regions. In areas with low fatality rates habits and attitudes toward alcohol are more effective.

Cruz (2020) disclosed that motorist and LTO Enforcers often obey and performed well in the implementation of the rules and regulations of R.A 10586 but they do not have the same responses.

Bagolong et al. (2014) found out that the traffic enforcement of the Traffic Management Center in Davao City in terms of traffic direction and control was very high, especially in directing the vehicles and pedestrians in the proper loading areas. They advise the general public concerning traffic congestion. The traffic enforcers showed very good performance in the apprehension traffic violators. Drivers apprehended violates the non-wearing of helmet or seatbelt, and driving under the influence of alcohol or drug. Strict traffic enforcement is observed but the respondents differ in their ability in the implementation. Vehicular accidents and accidents involving pedestrians is attributed on drivers attitude towards policies and the enforcement ability of the traffic enforcers.

In the province of Ilocos Norte, the drunk driving incidence is also a concern. Based on the official record of the Ilocos Norte Police Provincial Office, there were 858 alcohol-related vehicular traffic accidents from the year 
2013 to 2016: 220 incidents for 2013; 261 in 2014; 243 for 2015; and August 2016 is 134. In an interview with the media, the PCRB Head of INPPO said that it appeared that there is an increasing trend of vehicular traffic accidents around the province and accidents is caused by drunk driving(Ilocos Sentinel, 2016).

This scenario pushed the government to establish laws and ordinances to demand the compliance of motorists to lessen problems on traffic enforcement and to ensure the safety of the people. The law on RA 10586, known as the Anti-Drunk and Drugged Driving Act of 2013, provides a stiffer penalties to violators. The Land Transportation Office and the Philippine National Police are responsible in carrying out the provisions of the law concerning driver's education, apprehension, mandatory alcohol, and drug testing, random terminal inspection and information, education, and communication campaign.

Despite of the presence of the law and the conduct of information drive of the government, increasing trend of violations of the traffic rules and regulations is recorded including drunk driving which leads to a great extent of fatality to the persons involved. Human error is the main cause of traffic violations (Miguel et al. , 2014, Pungtilan et al., 2013).

This study determined the extent of implementation of the RA 10586 to minimize, if not eliminate the occurrence of the drunk driving violations.

\section{1 Theoretical Framework}

The Republic Act 10586 refers to the "AntiDrunk and Drugged Driving Act of 2013) states in its declaration of policy that the Constitutional principle recognizes the protection of life and property and the promotion of the general welfare as essential for the enjoyment of the blessing of democracy. Thus the State ensure road safety through the observance of the citizenry of responsible and ethical driving standards. Towards this end, the State shall penalize the acts of driving under the influence of alcohol, dangerous drugs, and other intoxicating substances and shall instill the standards of safe driving and the benefits derived from it through institutional programs and appropriate public information strategies.

\subsection{Statement of the Problem}

The assessed the level of implementation of RA 10586, specifically on the Anti-Drunk Driving.

It sought answers to the following questions:

1. What is the profile of the respondents?

\section{a. motorists}

1.1 age

$1.2 \operatorname{sex}$
1.3 civil status

1.4 educational attainment

1.5 occupation

1.6 type of driver's license, and

1.7 length of driving experience

1.8 trainings/seminars attended related to anti-drunk driving?

\section{b. law enforcement officers}

1.1 age

$1.2 \mathrm{sex}$

1.3 civil status

1.4 educational attainment

1.5 occupation

1.7 length of service

1.8 trainings/seminars attended related to anti-drunk driving?

2. What is the perceived level of implementation of RA 10586 as regards to:

2.1 drivers education during the processing of license

2.2 apprehension,

2.3 mandatory alcohol testing of a driver involved in motor vehicular accidents and 2.4 information, education, and communication campaign?

3. What are the problems encountered in the implementation of this law?

4. What plan can be developed to enhance the implementation of RA10586?

\section{METHODOLOGY}

The descriptive method of research was used to describe the implementation of RA 10586 and the problems encountered. It was conducted in the two cities, namely Laoag and Batac, and in the municipality of San Nicolas, Ilocos Norte, because they belong to the top 3 in terms of alcohol-related VTA's incidence rate from 2013-2017. There were 185 respondents in all; 114 are motorists and 71 law enforcement officers. Twenty percent $(20 \%)$ came from each locale based on the number of drunk driving accidents. Using total enumeration for the law enforcement officers. It utilized questionnaire to gather data and followed by an unstructured interview. Frequency and percentage were applied to interpret the profile and problems encountered and weighted mean for the level of implementation of the law based on a 4 point Likert Scale. 


\section{RESULTS AND DISCUSSIONS}

\section{Profile of the Respondents}

\section{Motorists}

There are more male motorists than female, majority are single (68 or $59.65 \%$ ) and belongs to the age range of 28-37, they attained up to college level and are employed. The data also showed that majority possessed a professional driver's license (65 or 57.01) and have enough experienced in driving wherein they had been driving for almost 11-15 years. The motorists had undertaken some seminars, which are more on RA 10586. It appeared that not all of them undertake the seminars. According to some respondents, they obtained these seminars during meetings in barangay assembly, tricycle driver's association, riders club, and in school. Portman et al., (2013) states that a typical drunk driver is a man aged 40-49 and 22 to 25 (Hingson and Winter, 2009), who has a job and married. Men have five times higher risk of drunk driving than for women.

\section{Law Enforcement Officers}

There are more male law enforcers (66 or $92.95 \%)$; the female counterpart is very few because of the nature of work. The majority are married (56 or $78.87 \%$ ), belong to the age range of 26-37 (34 or 47.88), and attained college level $(90.14 \%)$. Most of them are traffic enforcers (43 or 60.56) and had been in the service for 610 years (42 or $59.15 \%)$ and received seminars and training related to RA 10586 and the traffic rules and regulations which equipped them with knowledge and skills on how they implement the law. Not all of them attended formal seminars; however, in a conversation with a traffic police officer, they also conduct re-echo while they are in the office.

\section{Level of Implementation of RA 10586 Perceived by the Motorists}

Generally, motorists perceived the implementation of the anti-drunk driving law was just often (2.98), as evident in its overall mean. The implementors still have some lapses in doing their responsibility and wanting for improvement to ensure the proper implementation of the provisions of the law. The result is the same as the findings of Cruz (2020), who states that enforcers often performed well the rules and regulation of R.A 10586.

Drivers Education. Table 2 disclosed that driver's education is often implemented as evident in its average mean of 2.83 . The result signifies that driver's education is religiously and substantially conducted by the implementers to increase awareness of the motorists. However, there is still a need to fill in the gap to make sure that it is always conducted. Educating the motorists, is a must, and the fact that it serves as a preventive measure to ensure the safety of everybody.

Of all the criteria, the conduct of written examination for the application of a drivers license was the only one which is always (4.00) implemented. All the respondents said that they took the test. However, some motorists felt that the examination was just for formality, and they do not even know if they really pass or not. A female respondent admitted, "Nag exam ak idi, ngem kasla compliance lang dika pay ammo nu ana resulta sakanto mapan agbayaden" (I took the examination, and it seems that it is just for compliance I do not even know the result then you go for payment). Another motorist affirmed “Adda written test na ken adda fixer ko" ( a written exam, and I had a fixer).

Some activities under drivers education were often implemented like the conduct of orientation on the effects of drinking liquor in their driving ability (2.71), the hazards brought by drunk driving (2.70), penalties for violation of the law (2.67) and educating drivers in the process of renewal (2.63). It can be inferred from the results in motorists were not properly oriented, which could result in a lack of awareness. The improper implementation of this activity will contribute to an increase in law's violation since they do not know the penalties then they will just drink liquor and drive. Emphasizing on the penalties, may serve as a deterrent factor for motorists not to drive under the influence of alcohol, knowing that they will pay a fine which is considerably expensive and may even lead to imprisonment. Awareness on the law cultivates a profound sense of responsibility from among motorists; accordingly, knowledge is power. An individual may lack orientation about statutory provisions for alcohol-impaired driving (Sloan et al., 2013, Erickson et al., 1977; Nagin, 1998; Pogarsky et al., 2004; Kleck et al., 2005). The law enforcers and motorists are less aware on the provisions of RA 10586 (Labra et al., 2016).

The researcher asked a motorist if he knows about the effects of drinking liquor in driving a vehicle. He responded, "Wen, makaridep ka nu dadduma, aglallo no adut naimom ken dimo makontrol ti pinagpataray." (Yes, I feel drowsy while driving, especially if I have high intake of liquor and I cannot control my speed). To follow-up, he was asked regarding penalties in violation of the antidrunk driving law, and he answered, "Diak ammo ta di met naibaga idi" (I do not know because I was not informed.). A respondent mentioned that, "Adda met bassit naibaga da panggep ti epekto ti arak ken imbaga na nga isu ti makagapu nu apay adu ti madesdesgrasya, isu lang" (The information on the effects of liquor was just 
limited, and I was told that it is the common causes of accidents).

The provision of module for drivers education is sometimes (2.29) implemented which obtained the lowest mean. Not all motorists are provided with a module which could help them to improve their awareness. It implies that non-distribution of module affects the consciousness and compliance of the motorists. There is a problem with the implementation of this activity. When the respondents are asked if they received a module as part of drivers' education, not all of them were given.

Apprehension. The apprehension of violators of the anti-drunk and drugged driving act is often (3.49) implemented. Full implementation was not attained, however it is good enough, and there is more to improve. In the apprehension process, legal provisions must be satisfied, and with this result, it only manifest that the motorist are knowledgeable how a law enforcer should apprehend a violator. Three of the criteria were always implemented, like the automatic revocation of license upon refusal for mandatory testing (4.00), the effecting of arrest when BAC is more than the prescribed limit (3.85), and observance of proper arrest procedures (3.68). It shows that the motorists were given correct treatment whenever they have an encounter law enforcers. It also signifies that the law enforcers are responsible enough in the performance of duties, and firm in implementing the law. They had shown commitment and dedication as law enforcers and it is highly commendable. Their profile, particularly on their maturity, education, years of service, and training could have helped them in the proper implementation.

In a conversation with a motorist respondent, he mentioned that "Kasaritak diay traffic enforcer idi natiliw ak ken pasuksukak ket madi na kayat, adda prinsipyo na" (I tried to talk with the traffic enforcer who happens to catch me and I bribe him but he did not like it, he is a principled person).

But for some activities in the stage of apprehending the motorist rated it as often implemented on the determination of the probable cause (2.95), screening using the field sobriety test on site (2.85), and the impounding of a vehicle if BAC is detected high (3.38) because in the experiences of the motorists they were apprehended not only the way they drive the vehicle, but when stopped for a checkpoint, the law enforcers could also detect using their sense of smell when they will have a conversation. In the conduct of the field sobriety test, it is not always performed, especially if the motorist, has already other means of detecting the person if he is drunk or not, like the portable test kits to examine if the person is under the influence of liquor. In the aspect of impounding of a vehicle of violators of drunk driving, there is some motorist who is brave enough to talk with the law enforcers and convincing not to impound their vehicle. In some instances, if the violator has the influence of a relative of a law enforcer then they will not confiscate the car or motorcycles. The situation tells that the law enforcers are slightly negligent in the act of impounding vehicles.

A motorist involved in a drunk driving accident honestly admitted, "Saan da imbati diay motor ta adda amammo tay nanang tay kadduak a nadesgrasya" (They did not impound my motor vehicle was not confined because the mother of my companion in the accident knows somebody in the law enforcement team).

Mandatory Alcohol Testing of Driver Involved in Motor Vehicular Accidents. The data revealed that this activity is often enforced as shown in its average mean of 2.92. Since this is a mandatory requirement, there is substantial compliance from the implementors.

The automatic revocation of drivers' license upon refusal to undergo mandatory testing is always (3.74) implemented. This is the primary basis of the law enforcer to charge a motorist for violation of RA 10586. That is why they conduct it all the time. It also manifests that they are firm in the implementation of the law and the motorist is cooperative in this process.

A motorist who had been involved in an accident due to drunk driving confessed that "Idi imbaga da nga alcohol test sen dak, ket diak nagkitakit ta ammok met nga protocol da dayta." (When I was told to have the acohol test, I did not refuse because I know that it is a part of their protocol).

Someone added that, "Nagboluntaryo ak nga ma alcohol test tapno makita da nu nangato ti alcohol ti bagik wenno saan." (I volunteered myself for an alcohol test so that they could check if my blood alcohol content is high or not).

The Nationwide Random Terminal Inspection and Quick Random Drug Tests are often (2.62) implemented. It suggests that this activity is frequently conducted for some reasons like if there are mass fatalities brought by vehicular traffic accidents then and there they will become strict to big transportation companies. Also, in the time of summer vacation, all saints day, all souls day, holy week, and Christmas and new year celebrations, the implementors visits terminal to inspect since these are the events of which people usually travel from one place to another using a vehicle. A jeepney driver said, "Manmano nga umay da ag inspect, nu lang adda mairana nga nakaro a aksidente ken panawen ti bakasyon." (They 
rarely conduct an inspection, if there are just fatal accidents and during vacation).

As to the conduct of site field sobriety test, it is sometimes (2.40) implemented. The motorist finds that it is no longer applicable since there are already portable test kits to directly examine the person if he had alcohol intake. If the motorist suffered from a fatal accident, they immediately rush him to the hospital since there is no more time to conduct the said test. It implies that the applicability of this test is on case to case basis.

A respondent narrated that, "Nakadungpar ak $t i$ naka parking a tricycle gapu ti bartek ko, nagresponde dagiti police, naangut dak nga nasanger, in alcohol test dak ti inusar da ket papel, inpan dak paylang diay health center ta isu ti kaasitgan tapno mausawanak ket idin pinagawidakon gapu ta saan met a nakaro unay ti damage ko." (I bumped a parked tricycle because I was under the influence of liquor, and the police responded, and they happen to smell alcohol odor on me. The police officer conducted, alcohol test using a strip of paper, and they accompanied me to the nearest health center for me to overcome my drunkenness. They let me go home because I just had slight damage.)

Another motorist who suffered an accident stated that "Idi nadisgrasya nakaro sugat ko, immay ti police ngem awan met dayta field sobriety test, kasi madlaw dan nu nabartek ka, sigud impan dak hospital." (When I had an accident I had fatal injuries, the police came but they did not conduct a field sobriety test, they already knew if you are drunk, they immediately rushed me to the hospital.)

\section{Information, Education and Communication}

Campaign. The implementation of information, education, and communication campaigns is often (2.67) implemented because there is information drives conducted by the police organization through their PCAD units, like the distribution of flyers and the conduct of seminars. It signifies that they responsibly inform the motorist and every member of the community. The information campaign using the media (2.85) obtained the highest mean because people keep themselves aware through radios, televisions, and social media. It is often that there are news about vehicular traffic accidents due to drunk driving and they take advantage of reminding the motorist not to drink and drive and follow traffic rules and regulations. With the media, the motorists is equipped with relevant information's particularly the provisions of RA 10586. As experienced by some motorists, they were able to have an awareness about drunk driving during the barangay assembly, which is discussed by a police officer. The provision of examination in the renewal of ID is sometimes (2.47) implemented having the lowest weighted mean. Some of the respondents did not take the exam in renewing their IDs. The law enforcers rated the implementation of the RA 10586 as often implemented which obtained an overall mean of 2.78. It signifies that they are substantially performing well their duties and responsibilities.

Apprehension. In apprehending violators, the law enforcers often (3.58) implement their duties and responsibilities. Results, manifest the sincerity of the implementors towards their job, but it is still wants for improvement to improve the delivery of their services. Dacalanio (2017) also found out that traffic enforcers show moderate competencies because they possess minimum knowledge, skills, and understanding; thus, training and development is a priority needs.

The majority of the provisions in the apprehension stage are always (4.00) implemented, and the highest is the confiscation and automatic revocation of a license if driver refuses mandatory testing. Respondents had undergone training and orientation because the conduct of test is mandatory. It implies that they have commitment to the performance of their sworn duties as law enforcers. The data also disclosed that they often implement some procedures like determining a probable cause (3.36), the determination of driver's BAC level (3.16), and the screening using field sobriety test on site (3.00) having the lowest mean. The law enforcers do not only rely on these procedures to determine that the motorist is drunk or not because they also apprehend during the conduct of a regular checkpoint. Sometimes, the field sobriety test is disregarded since some law enforcers would immediately conduct the alcohol test and they also uses their common sense as they examine the motorists.

Based on the interview, a law enforcer mentioned, "Nu adda maobserbarak nga lugan nga sobra paspas na, isu nukua paka riknaak nga baka nakainom isu nga pasardengek" (If I happen to observe overspeeding vehicle I felt that the driver is under the influence of liquor, so I have to stop him.) Another respondent claimed that, "Alistom la madlaw tay tao nu nabartek, uray dimo pag field sobriety test, deretsuem nga ti alcohol test." (It is easy to detect if the dirver is drunk even you will not conduct the field sobriety test, immediately do the alcohol test.)

Mandatory Alcohol and Chemical Testing of Driver Involved in Motor Vehicular Accidents. Regarding this procedure, it is often (3.23) implemented because not all motorists involved in drunk driving be engaged in vehicular accidents. It suggests that these are just implemented on case basis. 
The confiscation and automatic revocation of licenses of drivers' upon refusal to undergo mandatory testing are always (4.00) implemented it is because the result of the mandatory testing is the very basis of the law enforcer in charging in terms of criminal liability and damages incurred. The law enforcers are firm in performing this provision of law, and it manifests their competence. The conduct of on-site field sobriety test on a driver involved in a vehicular accident resulting in the loss of human life or physical injuries are often (3.47) implemented. The law enforcers do not perform in most cases since they immediately endorsed the person for an alcohol test and they can easily observe if the motorist is drunk, not only on posture or movements since they could also smell their odor. The conduct of Nationwide Random Terminal Inspection and Quick Random Drug Tests is sometimes (2.22) implemented, which obtained the lowest mean. Very few are involved, and it is only done occasionally hence this result.

\section{Information, Education and Communication}

Campaign. The law enforcers respond that they sometimes implement the information drive activities provided by this law, as evident in its average mean of 1.54. Results implies that not all of the respondents partake in the implementation of this activity because in the conduct of campaigns there are assigned focal persons incharged for this undertaking. Like in the PNP, they have their police-community officers who will be involved in the IEC campaign to the community of which they are invited to speak during barangay assemblies, meetings of drivers association and even in educational institutions. The law enforcers have limited involvement in the information drive.

Drunk driving orientation is sometimes (1.60) implemented when the motorists claimed their ID manifests a lack of aggressiveness in educating the motorists as a way of reminding them to become responsible motorists. It can be noted that the conduct of drunk driving orientation thru media is sometimes (1.52) implemented. The result signifies that only a few are involved in this undertaking because, as mentioned above, there is appointed spokespersons. There are also instances that some law enforcers are interviewed on the spot by media reporters regarding a vehicular accident related to drunk driving and they take that opportunity to remind the motorists about the law, and their compliance with it. As observed by the researcher, a police officer is invited by a TV station, and there he discusses the status on traffic violations, and giving emphasis on anti-drunk driving law. Consequently, the conduct of drunk driving orientation thru the Pulung-pulong/Rang-ay ti Barangay is also sometimes (1.51) implemented. In this activity, police officers are mostly involved conducting lectures in this venue and at the same time, distribution of flyers takes place, so traffic enforcers have no direct involvement hence this result.

\section{Problems Encountered in the Implementation of the Law}

The problems encountered by the motorists with the law enforcers as they implement the law. The respondents gave multiple answers, which are represented with the given percentage. As gleaned from the figure, the law enforcers are lax in dealing with the motorist as they implement the law, which obtained the highest percent $(30 \%)$. This usually happens because some motorists will also try to talk and settle with the law enforcers or they have influential relatives in the PNP or from the political arena. It signifies that they do not strictly implement the law. Being discourteous $(27 \%)$ and showing misconduct also has a significant contribution to their problems with $23 \%$. This scenario happens because some law enforcers cannot probably control themselves, especially if the motorist is arrogant and make a prolong argumentation.

To some extent, some law enforcers had the feeling that they are so powerful, that they forget themselves as public servant. They still lack the essential traits that would help them become effective law enforcers of the law on RA 10580. It is good to note that there is a very low percentage of corruption (1\%) encountered which implies that they internalized the value of integrity and credibility. Results, suggest that they do not strictly adhere to the principle of maximum tolerance.

In the interview conducted, ten (10) respondents gave positive feedback telling that the law enforcer was nice in his dealings. On the other hand, a motorist claimed, "Nasayaat ngamin diay pulis isu nga dina in impound diay lugan ko." (The police is so kind that is why my vehicle was not hold). A male motorist who is a security guard confessed that "Nu adda am ammom nga adda impluwensya na, saan da alaen ta lugan mo" (If you know somebody who has the influence, they will not impound your vehicle). A student motorist confessed that "Pinadas ko kinasarita diay nangtiliw kaniak ken pasuksukak ngem, tiniketan nak latta. Saan a kurakot isuna." (I tried talking to the one who caught me and offered an amount, but he still issued a citation ticket. He is not corrupt).

The law enforcement officers disclosed that motorist disrespect and show of bad behavior is prevalent from among the respondents with $21 \%$. This is the usual reaction of motorists when they are apprehended; they try to argue until it will lead to misunderstanding. Consequently, the bribe offering of the motorist takes 
place with $17 \%$ of which this is their options not to be issued with citation ticket to escape penalties and bad record. In some instances, they also encounter dishonesty from the violators, tend to deny that they are drunk and creating numerous reasons for them not to be apprehended.

\section{Research Output}

The proposed action plan titled "Enhanced Strategies in the Implementation of RA 10586" was conceptualized to improve the implementation of the law with the following objectives: (1.) to establish a systematic implementation of the provision of the law, which ensures the delivery of quality services; (2.) to develop more accessible and friendly conduct of driver education; (3.) to highly equipped the law enforcement officers with the required competencies in the performance of duties; and (4.) to widen the linkages of the law enforcement agencies in educating the motorists.

\section{CONCLUSIONS}

Based on the findings, the conclusions are drawn:

1. The motorists are matured, males, married, college level, employed, qualified and well-experienced drivers. Meanwhile, the law enforcement officers are males, married, matured, college level, employed as traffic enforcers, have substantial work experience, and qualified.

2. The law is substantially implemented as perceived by the two group of respondents yet still wanting for improvement.

3. The problems encountered by the motorist and law enforcement officers are interrelated.

\section{ACKNOWLEDGEMENT}

The researcher acknowledges the Northwestern University for its full support in this research undertaking and also to the respondents for their full cooperation.

\section{REFERENCES}

[1] Ager, Maila (2016).10,000 vehicular accidents in first 4 months of $2016 \quad$ police https://newsinfo.inquirer.net/821966/10000-vehicular accidents-in-first-4-months-of-2016police\#ixzz5kNMBVb8d

[2] Bornewasser, M. and Glitsch, E. (2000). Analyzing the Decision Making Process of Drunk Drivers Before Driving

[3] Brady, Joanne, E. and Li, Guohua (2012). Prevalence of alcohol and other drugs in fatally injured drivers https://doi.org/10.1111/j.1360-0443.2012.03993. Date retrieved: August 13, 2018
[4] Cinnamon, Jonathan, Schuurman, Nadine and Hameed, Morad (2011). Pedestrian Injury and Human Behaviour: Observing Road-Rule Violations at High-Incident Intersections

[5] Dacalanio, Jeanyben Torregoza M. (2017). Competencies of Traffic Managers and Traffic Enforcers of the City of Malaybalay: Basis for an Intervention Plan International Journal of Scientific \& Engineering Research Volume 8, Issue 9, September-2017 ISSN 2229-5518

[6] Fergusson, David M., Horwood, L. John and Boden, Joseph M. (2008). Is driving under the influence of cannabis becoming a greater risk to driver safety than drink driving? Findings from a longitudinal study

[7] Lyles, Derrell (2015). Traffic fatalities fall in 2014, but early estimates show 2015 trending higher (http://www.nhtsa.gov) Date retrieved: September 10, 2018

[8] DeJoy, DM. (1989). An attribution theory perspective on alcohol-impaired driving. Department of Health Promotion and Behavior, University of Georgia, Athens 30602. http://www.ncbi.nlm.nih.gov/

[9] Roberto, Andres L. (2014). Alcohol and Hospitalized Road Traffic Injuries in the Philippines Yale J Biol Med. 2014 Sep; 87(3): 307-319. 